\title{
Analysis of phthalates via HPLC-UV in environmental water samples after concentration by solid-phase extraction using ionic liquid mixed hemimicelles
}

\author{
Jidong $\mathrm{Li}^{\text {a,b }}$, Yaqi Cai ${ }^{\mathrm{a}, *}$, Yali Shi ${ }^{\mathrm{a}}$, Shifen Mou ${ }^{\mathrm{a}}$, Guibin Jiang ${ }^{\mathrm{a}}$ \\ ${ }^{a}$ State Key Laboratory of Environmental Chemistry and Ecotoxicology, Research Center for Eco-Environmental Sciences, \\ Chinese Academy of Sciences, Beijing 100085, China \\ ${ }^{\mathrm{b}}$ General Research Institute for Non-ferrous Metals, Beijing 100088, China
}

Received 16 April 2007; received in revised form 11 June 2007; accepted 11 June 2007

Available online 17 June 2007

\begin{abstract}
Ionic liquid mixed hemimicelles-based solid-phase extraction for the preconcentration of five phthalates in environmental water sample was inves-

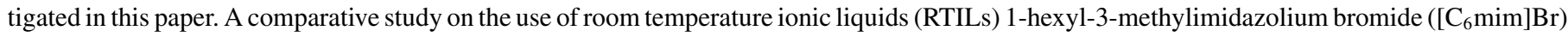
and 1-dodecyl-3-methylimidazolium bromide $\left(\left[\mathrm{C}_{12} \mathrm{mim}\right] \mathrm{Br}\right)$-coated silica as sorbents was presented. Owing to having bigger adsorption amounts for analytes $\left[\mathrm{C}_{12} \mathrm{mim}\right], \mathrm{Br}$-coated silica was selected as SPE material and the five analytes di-ethyl-phthalate (DEP), di- $n$-propyl-phthalate (DnPP), di- $n$-butyl-phthalate (DnBP), di-cyclohexyl-phthalate (DcHP) and di-(2-ethylhexyl)-phthalate (DEHP) can be quantitatively extracted under optimal conditions. The analytes retained on the cartridge were desorbed completely with $3 \mathrm{~mL}$ methanol (pH 2). Predominant factors influencing the extraction efficiency, such as RTILs concentration, $\mathrm{pH}$ value, ionic strength and breakthrough volume were discussed. The proposed method had been applied to determining the five phthalates in four environmental water samples and concentration factor of 600 was achieved easily. Detection limits obtained ranged between 0.12 and $0.17 \mu \mathrm{g} / \mathrm{L}$. The accuracy of this method was evaluated by recovery measurement on spiked samples, and good recovery results (85-107\%) with relative standard deviation (R.S.D.) of below 6\% were achieved.
\end{abstract}

(C) 2007 Elsevier B.V. All rights reserved.

Keywords: Ionic liquid; Mixed hemimicelles; Solid-phase extraction; Phthalates; HPLC-UV

\section{Introduction}

Phthalic acid esters (phthalates, PAEs) are widely used as polymer additives in the manufacture of plastics (primarily polyvinyl chloride), rubber and styrene to make them flexible. Globally, over 18 billion pounds of PAEs are used each year. They can be leached from the above-mentioned products and find a way to various environmental matrices such as environmental water, soil and plants [1-3]. Nowadays, due to its massive use and persistent character, PAEs are considered as ubiquitous environmental pollutants. A number of researches proved that PAEs exerted a pernicious impact on human health; furthermore,

\footnotetext{
* Corresponding author at: Research Center for Eco-Environmental Sciences, Chinese Academy of Sciences, P.O. Box 2871, Beijing 100085, China.

Tel.: +86 1062849182 ; fax: +86 1062849239 .

E-mail address: Caiyaqi@ rcees.ac.cn (Y. Cai).
}

some PAEs can cause endocrine system disorders [4,5], produce carcinogenic effects and afflict the development of reproductive system [6].

The very low concentration level of PAEs and the complex matrix of many environmental samples make sample preconcentration necessary for a reliable determination of these compounds. Several analytical methods have been developed for determining PAEs by gas chromatography (GC) [7,8], high performance liquid chromatography (HPLC) $[9,10]$ using different preconcentration techniques such as liquid-liquid extraction (LLE) [11], solid-phase microextraction (SPME) [12,13] and solid-phase extraction (SPE) [14-17] in several types of matrices. Among above-mentioned sample pretreatment procedures, solid-phase extraction based on different types of sorbents such as $C_{8}$ [15], organic polymers [16] was widely used.

Recently, a new SPE method based on hemimicelles and admicelles (mixed hemimicelles) has been proposed for the preconcentration of a variety of organic pollutants from complex 
environmental matrices $[9,18-20]$. The sorbents used are produced by adsorbing ionic surfactants (such as sodium dodecyl sulfate or cetyltrimethylammonium bromide) on the metal oxides (such as alumina or silica) surface. Mixed hemimicelles used in SPE have many advantages, such as high extraction efficiency, high breakthrough volume, easy elution of analytes and high flow rate for sample loading; furthermore, this kind of SPE technique requires no clean-up steps and the sorbents is easy to regenerate, and is thus able to meet the needs of rapid analysis.

Room temperature ionic liquids (RTILs) are ionic compounds that are liquids at ambient temperature and consist of ionic species [21]. RTILs belong to a relatively new class of solvents which are amphiphilic molecules with a hydrophilic polar headgroup (ionic in nature) and a hydrophobic hydrocarbon chain (the tail). In recent years, RTILs have attracted great attentions due to their unique chemical and physical properties such as nonvolatile (environmentally benign), excellent solvation qualities, non-flammable and high thermal stability $[22,23]$. As a result, RTILs are widely used in liquid-liquid extraction [24,25], synthesis [26,27], separation [28,29] and electrochemistry [30,31]. Some research groups have also studied the aggregation and micelles formation of ionic liquids in aqueous solution [32]. As RTILs can dissolve many kinds of organic, organometallic and inorganic compounds [33,34], their applications in analytical chemistry have also received attentions recently [35-39]. He et al. determined the testosterone and epitestosterone in human urine using cloud extraction method based on aqueous two-phase systems consisting of ionic liquid 1-butyl-3-methylimidazolium chloride, coupled with HPLC/spectrophotometry detection, the detection limit of $1 \mathrm{ng} / \mathrm{mL}$ was obtained [38]. Generally, cloud extraction method was a simple, rapid and effective sample pretreatment technique; however, some limitations still existed, such as the RTILs-rich phase was dense and it was not easy to be injected into HPLC for analysis; high concentration of ionic liquid in sampling solution may produce large interferential peaks.

In this paper, we investigated the applications of RTILs [ $\left.\mathrm{C}_{6} \mathrm{mim}\right] \mathrm{Br}$ and $\left[\mathrm{C}_{12} \mathrm{mim}\right] \mathrm{Br}$ mixed hemimicelles for the preconcentration of five phthalates DEP, DnPP, DnBP, DcHP and DEHP in environmental water sample. Mixed hemimicelles were prepared by adsorbing $\left[\mathrm{C}_{6} \mathrm{mim}\right] \mathrm{Br}$ and $\left[\mathrm{C}_{12} \mathrm{mim}\right] \mathrm{Br}$ on silica surface and predominant experimental factors affecting the extraction efficiency were studied. To the best of our knowledge, this was the first time that RTILs mixed hemimicelles-based SPE was applied for the pretreatment of PAEs in environmental water samples.

\section{Experimental}

\subsection{Chemicals and materials}

All reagents were of analytical grade and used as supplied. Five PAEs were obtained from Beijing Chemicals Corporation (Beijing, China). A stock solution containing $200 \mathrm{mg} / \mathrm{L}$ each phthalate was prepared in methanol and stored under dark conditions at $4{ }^{\circ} \mathrm{C}$. The RTILs $\left[\mathrm{C}_{6} \mathrm{mim}\right] \mathrm{Br}$ and $\left[\mathrm{C}_{12} \mathrm{mim}\right] \mathrm{Br}$ were supplied by Kemo Reagent Corporation (Hangzhou, China) and their structures were listed in Table 1. Silica was purchased from Sigma Corporation (Steinheim, Germany) and the physical properties were as follows: surface area $\left(300 \mathrm{~m}^{2} / \mathrm{g}\right)$; point of zero charge (PZC, 2.9); particle diameter range $(70-150 \mu \mathrm{m})$, mean pore size $(150 \AA)$ and density $\left(1.15 \mathrm{~cm}^{3} / \mathrm{g}\right)$. HPLC-grade acetonitrile and methanol were supplied by Merck Corporation (Germany). Water (18.3 M $\Omega$ ) used in all experiments was prepared using a compact ultrapure water system from Barnstead Corporation (Iowa, USA).

\subsection{Sample collection and preservation}

Effluent wastewater sample was collected from the Gaobeidian sewage treatment plant (Chaoyang District), the largest sewage treatment plants in Beijing. It is located in the east of Beijing and it receives about the same level of domestic and industrial wastewater. River water samples were taken from the Xiaoqing River (Haidian District, Beijing) and Jingmi Canal (Haidian District) in November 2006. Tap water sample was taken from our lab in Haidian District. All water samples were collected randomly. Samples were collected into pre-cleaned, light-preserved glass bottles and $5000 \mathrm{~mL}$ each sample was filtered immediately through $0.22 \mu \mathrm{m}$ nylon membranes in order to remove suspended solids. We realized that these filters maybe contain a considerable amount of phthalate such as DnBP, so their cleaning with acetone was carried out prior filtration. The

Table 1

Chemical structure of RTILs [ $\left.\mathrm{C}_{6} \mathrm{mim}\right] \mathrm{Br}$ and $\left[\mathrm{C}_{12} \mathrm{mim}\right] \mathrm{Br}$

\begin{tabular}{lll}
\hline Name & Molecular formula & Sbbreviation \\
1-Hexyl-3-methylimidazolium bromide & & $\mathrm{C}_{10} \mathrm{H}_{19} \mathrm{~N}_{2} \mathrm{Br}$ \\
1-Dodecyl-3-methylimidazolium bromide & $\mathrm{C}_{16} \mathrm{H}_{31} \mathrm{~N}_{2} \mathrm{Br}$ &
\end{tabular}


filtered samples were adjusted to $\mathrm{pH} 2$ with $1 \mathrm{M} \mathrm{HNO}_{3}$ and stored at dark conditions at $4{ }^{\circ} \mathrm{C}$ until analysis.

\subsection{SPE based on mixed hemimicelles}

An extraction cartridge was prepared by using a SPE plastic tube $(6 \mathrm{~mL}$, polypropylene) and $0.5 \mathrm{~g}$ silica was packed into it. To prepare mixed hemimicelles column, $25 \mathrm{~mL}$ solution containing $25 \mathrm{mg}\left[\mathrm{C}_{12} \mathrm{mim}\right] \mathrm{Br}$ was passed through the cartridge column, then the water samples was adjusted to $\mathrm{pH} 6.5$ and passed through the column. Sample loading was performed by using a DOA-PIOU-BN vacuum pump (Michigan, USA) at a flow rate of $5 \mathrm{~mL} / \mathrm{min}$. Target analytes were eluted with $3.0 \mathrm{~mL}$ methanol ( $\mathrm{pH} 2)$ and dried with a stream of nitrogen at $60^{\circ} \mathrm{C}$, followed by dissolved in $0.5 \mathrm{~mL}$ methanol. The methanol solution was vibrated in an ultrasonic bath for $5 \mathrm{~min}$ in order to insure that the phthalates can be dissolved into methanol completely. Finally, a $20 \mu \mathrm{L}$ of the solution was injected into the HPLC system for analysis.

\subsection{HPLC analysis}

The five phthalates were separated and quantified by using a liquid chromatography-spectrophotometry system (P680 HPLC Pump with a PDA100 Photodiode Array Detector, Dionex, USA) with an automatic sample injector (ASI-100, Dionex, USA). The analytical column was a $250 \mathrm{~mm}$ Diamonsil- $\mathrm{C}_{18}$ column ( $4 \mu \mathrm{m}$ particle diameter and $4.6 \mathrm{~mm}$ i.d.) supplied by Dikma Technologies Corporation (Beijing, China). The mobile phase consisted of acetonitrile and water (acetonitrile: water, 75:25, $\mathrm{v} / \mathrm{v}$ ) and the flow-rate was set at $1 \mathrm{~mL} / \mathrm{min}$. Spectrophotometry detection of analytes was performed at $226 \mathrm{~nm}$ wavelengths.

\subsection{Adsorption studies}

The adsorption studies were carried out in batch mode and all experiments were carried out at $25 \pm 1^{\circ} \mathrm{C}$ in a water bath. Both the adsorption isotherms of $\left[\mathrm{C}_{6} \mathrm{mim}\right] \mathrm{Br}$ and $\left[\mathrm{C}_{12} \mathrm{mim}\right] \mathrm{Br}$ on silica were obtained by adding $0.5 \mathrm{~g}$ silica to $25 \mathrm{~mL}$ aqueous solution containing $\left[\mathrm{C}_{6} \mathrm{mim}\right] \mathrm{Br}$ or $\left[\mathrm{C}_{12} \mathrm{mim}\right] \mathrm{Br}(0-50 \mathrm{mg})$, and the initial $\mathrm{pH}$ of solutions was adjusted to 6.5. After vigorous stirring of the solutions for $5 \mathrm{~min}$, partial solution of every glass vial was centrifuged at $4000 \mathrm{rpm}$ for $10 \mathrm{~min}$. The concentration of $\left[\mathrm{C}_{6} \mathrm{mim}\right] \mathrm{Br}$ and $\left[\mathrm{C}_{12} \mathrm{mim}\right] \mathrm{Br}$ in the supernatants was determined by ESI-MS (ABI, USA) at $\mathrm{m} / z 251$ and 167 through different factors of diluting, respectively. The analysis was carried out in the "ESI (+) mode" and the operational parameters used were as follows: Declustering potential, $-30 \mathrm{~V}$; entrance potential, $-2.8 \mathrm{~V}$; collision cell entrance potential, $-11 \mathrm{~V}$; collision energy, $-13 \mathrm{~V}$; collision cell exit potential, $-4.5 \mathrm{~V}$; source temperature, $300^{\circ} \mathrm{C}$ and maximal accumulation time, $50 \mathrm{~ms}$. The zeta-potentials of solutions (after centrifuged) were determined with an zetasizer 2000 apparatus (Malvern, United Kingdom).

The effects of RTILs concentration, $\mathrm{pH}$ value and ionic strength on the adsorption were studied by mixing $25 \mathrm{~mL}$ aqueous solution containing $1.0 \mathrm{mg} / \mathrm{L}$ of DEP, DnPP and DnBP each with $0.5 \mathrm{~g}$ silica. Adsorption studies did not involve DcHP and DEHP owing to their low solubility in water. Both the added amounts of $\left[\mathrm{C}_{6} \mathrm{mim}\right] \mathrm{Br}$ and $\left[\mathrm{C}_{12} \mathrm{mim}\right] \mathrm{Br}$ were varied in the range of $0-50 \mathrm{mg}$. The solution was vigorously stirred for $5 \mathrm{~min}$, and then it was centrifuged at $4000 \mathrm{rpm}$ for $10 \mathrm{~min}$. The concentration of PAEs in the supernatants was determined by LC-spectrophotometry.

\section{Results and discussion}

\subsection{Adsorption isotherms of RTILs on silica particles}

The adsorption isotherms of RTILs on silica were useful for understanding the theory of extraction process and optimizing the SPE conditions. As can be seen from Fig. 1 that, before a certain loading point reached (approximately 0.6 and $0.4 \mathrm{mg} / \mathrm{g}$ for $\left[\mathrm{C}_{12} \mathrm{mim}\right] \mathrm{Br}$ and $\left[\mathrm{C}_{6} \mathrm{mim}\right] \mathrm{Br}$, respectively), nearly no RTILs were left in the aqueous phase. With the increase of RTILs concentration, both the adsorption amounts of RTILs on silica increased gradually. Maximum adsorption approximately 8 and $14 \mathrm{mg} / \mathrm{g}$ for $\left[\mathrm{C}_{6} \mathrm{mim}\right] \mathrm{Br}$ and $\left[\mathrm{C}_{12} \mathrm{mim}\right] \mathrm{Br}$ were obtained respectively when the concentration of $\left[\mathrm{C}_{6} \mathrm{mim}\right] \mathrm{Br}$ and $\left[\mathrm{C}_{12} \mathrm{mim}\right]$ $\mathrm{Br}$ was about 65 and $80 \mathrm{mg} / \mathrm{L}$, respectively. The amounts of RTILs adsorbed onto silica were clearly a function of the alkyl
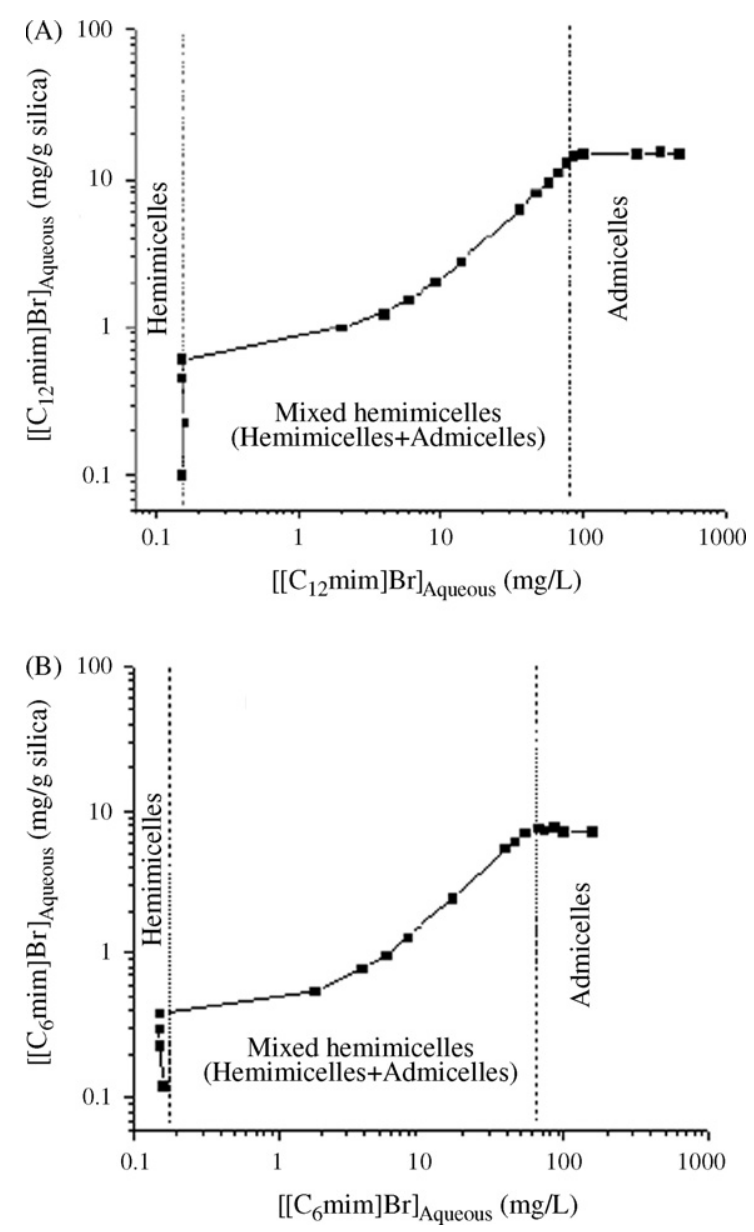

Fig. 1. Adsorption isotherms of RTILs on silica at $\mathrm{pH}$ 6.5: (A) $\left[\mathrm{C}_{12} \mathrm{mim}\right] \mathrm{Br}$ and (B) $\left[\mathrm{C}_{6} \mathrm{mim}\right] \mathrm{Br}$. 
chain length. These adsorption isotherms did not fit conventional adsorption models (e.g. Langmuir) very well, which was probably because adsorbing RTILs onto silica surface was not a simple surface phenomenon but a multistep process involving different kinds of interactions. Generally, ionic surfactant adsorption isotherms on metal oxides can be divided into three regions $[40,41]$. In the first region the adsorbed ionic surfactant molecules spread themselves on the surface to form singlelayer coverage (hemimicelles), probably through coulombic attractive interactions between charged metal oxides surface and the oppositely charged surfactants head group. The second region involves hydrophobic and electrostatic interactions, which result in the formation of bilayers (admicelles). The process of solubilizing analytes in hemimicelles and admicelles (mixed hemimicelles) is termed as "adsolubilization". Both the above-mentioned regions were suitable for SPE method. At the end of isotherm region the overall surface of metal oxide is compensated and surfactants begin to form micelles in solution, which may result in the solubilization of analytes into micelles in bulk solution again and this isotherm span is unsuitable for SPE.

\subsection{Effect of RTILs concentration on the zeta-potential of silica particles}

Zeta-potential measurements can provide very useful information on adsorption phenomena since changes in the zeta-potential reflect the adsorption on surface directly. In order to study the process of self-aggregated micelles formed on metal oxide surface, many research groups investigated the zetapotential curves of ionic surfactants adsorbed onto various metal oxides surfaces [42-44]. Fig. 2 showed that the zeta-potential of silica particles was a function of RTILs concentration. It can be observed that both the zeta-potentials of silica increased from negative to zero and converted to positive with increasing RTILs concentration. The zeta-potential changes can be interpreted as follows. At first the silica particles had a negative zeta-potential for the reason that the solution $\mathrm{pH}$ was higher than the silica PZC (about 3.0). At low RTILs concentrations ( $<5 \mathrm{mg}$ added amount) a zeta-potential plateau of two systems about $-13 \mathrm{MV}$ was observed, which indicated that the RTILs adsorption amounts were not detectable. With the increase of RTILs concentration, the RTILs molecules began to adsorb on

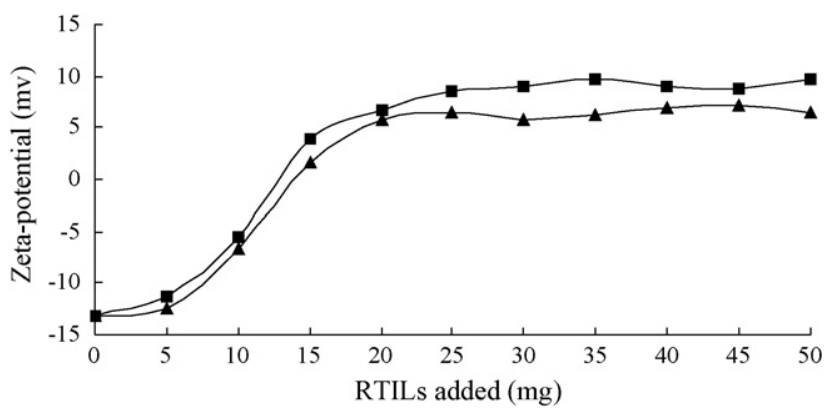

Fig. 2. The zeta-potential of silica particles as a function of RTILs concentration at $\mathrm{pH}$ 6.5: (ם) $\left[\mathrm{C}_{12} \mathrm{mim}\right] \mathrm{Br} ;(\boldsymbol{\Delta})\left[\mathrm{C}_{6} \mathrm{mim}\right] \mathrm{Br}$. negatively charged silica surface obviously through electrostatic attraction interactions, and the self-assembled surface micelles were formed gradually. The formed micelles screened the partial negative charges of silica surface, which resulted in a less negative zeta-potential. With the sign reversing after passing through a zero zeta-potential, the zeta-potential became positive with further RTILs adsorption, and attained a maximum of 9.8 and $7.2 \mathrm{MV}$ when the added amounts of $\left[\mathrm{C}_{12} \mathrm{mim}\right] \mathrm{Br}$ and $\left[\mathrm{C}_{6} \mathrm{mim}\right] \mathrm{Br}$ were about 25 and $20 \mathrm{mg}$, respectively. The zeta-potential values did not change with a further increase in RTILs concentration, indicating the silica surface was saturated by RTILs adsorption. After compensation of the surface charge, the zeta-potential became almost independent of the RTILs concentration.

\subsection{Sorbent selection}

Fig. 3 depicted the adsorption percentages of adsorbed PAEs as a function of the RTILs amount added. In the absence of RTILs, the PAEs hardly adsorbed onto the silica surface. In contrast, with increases in RTILs concentration, both the PAEs adsorption amounts of micelles systems increased remarkably. The increase in adsorption amounts can be explained by the gradual formation of mixed hemimicelles (hemimicelles and admicelles) on silica surface, and then the analytes were extracted gradually. Maximum adsorption percentages were obtained when the added amounts were in the range of $15-30 \mathrm{mg}$ for [ $\left.\mathrm{C}_{12} \mathrm{mim}\right] \mathrm{Br}$ and $10-20 \mathrm{mg}$ for $\left[\mathrm{C}_{6} \mathrm{mim}\right] \mathrm{Br}$, respectively. Both the DnBP maximum adsorption percentages were above $90 \%$; the main difference was the maximum adsorption percentages of DEP and DnPP, which were about 70 and $85 \%$ for $\left[\mathrm{C}_{12} \mathrm{mim}\right] \mathrm{Br}$-coated silica system while 60 and $80 \%$ for
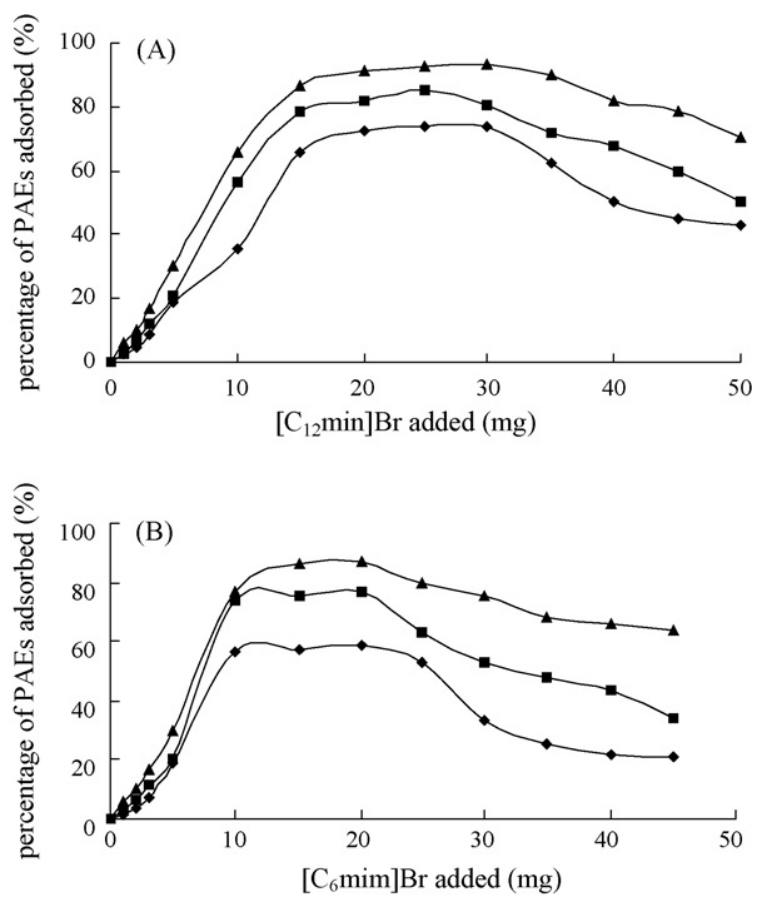

Fig. 3. Effect of the added amounts of (A) $\left[\mathrm{C}_{12} \mathrm{mim}\right] \mathrm{Br}$ and (B) $\left[\mathrm{C}_{6} \mathrm{mim}\right] \mathrm{Br}$ on the PAEs adsorption percentages at pH 6.5: (ム) DnBP; (ם) DnPP; ( $)$ DEP. 

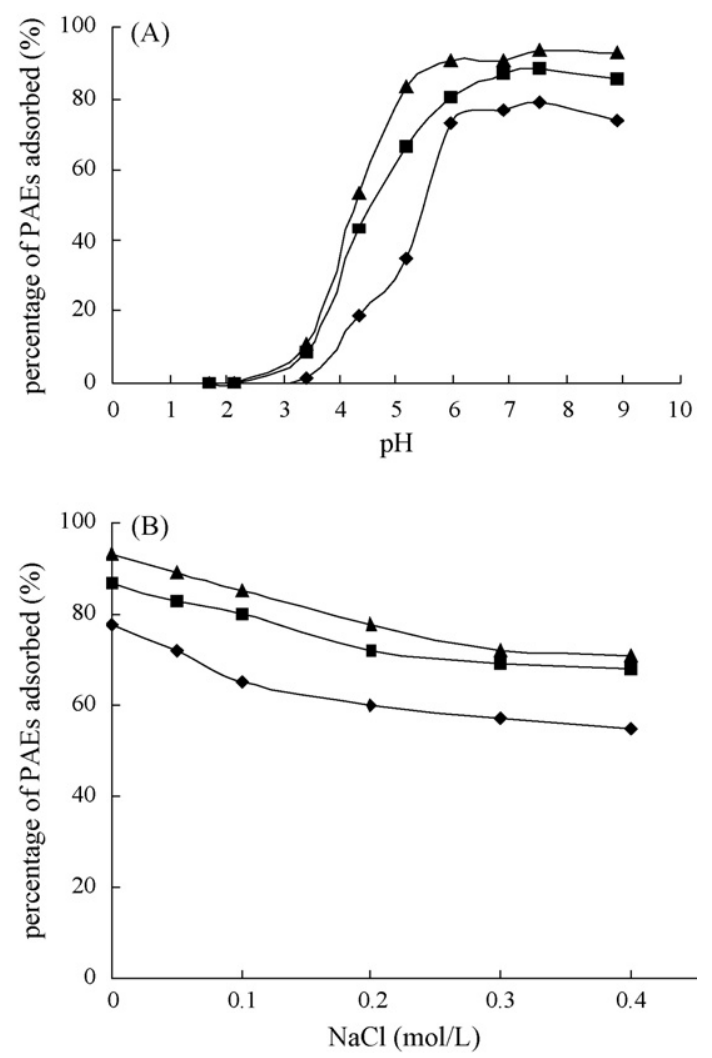

Fig. 4. Effect of (A) $\mathrm{pH}$ and (B) ionic strength on the extraction percentages: $(\boldsymbol{\Lambda})$ DnBP; (ם) DnPP; ( $)$ DEP.

$\left[\mathrm{C}_{6} \mathrm{mim}\right] \mathrm{Br}$-coated silica system, respectively. The experimental results also indicated clearly that the adsorption amounts had a positive relationship with the RTILs alkyl chain length. After a maximum adsorption plateau, the adsorption amounts began to decrease when the added amounts exceeded $30 \mathrm{mg}$ for $\left[\mathrm{C}_{12} \mathrm{mim}\right] \mathrm{Br}$ and $20 \mathrm{mg}$ for $\left[\mathrm{C}_{6} \mathrm{mim}\right] \mathrm{Br}$, which can be explained that with more ionic liquids added the RTILs molecules began to form micelles in the bulk aqueous solution; furthermore, the micelles made the PAEs redistribute into the solution again. Given these findings, the $\left[\mathrm{C}_{12} \mathrm{mim}\right] \mathrm{Br}$ adsorption system had higher adsorption amount than $\left[\mathrm{C}_{6} \mathrm{mim}\right] \mathrm{Br}$ and was more suitable for SPE method; therefore, $25 \mathrm{mg}$ [ $\left.\mathrm{C}_{12} \mathrm{mim}\right] \mathrm{Br}$ was adopted in the following studies.

\subsection{Effect of $p H$}

$\mathrm{pH}$ is one of the prime factors influencing the adsorption behavior of a mixed hemimicelles system. In present study the effect of $\mathrm{pH}$ was examined by varying $\mathrm{pH}$ between 1.5 and 9.0.
As shown in Fig. 4(A), the [ $\left.\mathrm{C}_{12} \mathrm{mim}\right] \mathrm{Br}$-coated silica system exhibited no obvious adsorption for three PAEs when $\mathrm{pH}$ was between 1.5 and 3.5. With the increase of $\mathrm{pH}$, the PAEs adsorption amounts increased dramatically before reaching a maximum above $\mathrm{pH}$ 6.0. This can be attributed to the fact that the silica surface was positive charged when the $\mathrm{pH}$ was below its PZC (2.9) and the $\left[\mathrm{C}_{12} \mathrm{mim}\right]^{+}$was hardly adsorbed to the silica surface. With increases in $\mathrm{pH}$ value, the silica surface gradually became negative charged such that there was a strong electrostatic attraction interaction between RTILs molecules and the negatively charged silica surface, which was sufficient to produce a great adsorption affinity for PAEs. Therefore, $\mathrm{pH} 6.5$ was selected for the following studies.

\subsection{Effect of ionic strength}

$\mathrm{NaCl}$ concentration ranged between 0.05 and $0.4 \mathrm{M} / \mathrm{L}$. It can be seen from Fig. 4(B) that the adsorption amounts of three PAEs decreased with increasing ionic strength. The experimental results suggest that the role of electrostatic interactions in the adsorption process was significant and the competition of sodium ions for the silica substrate was existed obviously. As we known that in the first adsorption region the adsorbed RTILs ions spread themselves on the silica surface to form a singlelayer coverage through coulombic attraction interactions. As a result, the effect of salt concentration was to suppress the thickness of electrical adsorption layer at the silica/solution interface, which led to the decrease of mixed hemimicelles formed on the silica surface.

\subsection{Breakthrough volume and desorption}

The breakthrough volume for PAEs was determined using a series of different volume aqueous solution $(100-500 \mathrm{~mL})$ spiked with $1 \mu \mathrm{g}$ of each the PAEs at $\mathrm{pH}$ 6.5. Insufficient recovery was considered to occur when the recovery was below $90 \%$. With the increase of solution volume, insufficient recoveries occurred when aqueous solution volume was above $300 \mathrm{~mL}$; for instance, the recovery of $78,82,85,86$ and $89 \%$ for DEP, DnPP, DnBP, DcHP and DEHP were obtained respectively when the passing volume was $400 \mathrm{~mL}$. The sample loading rate experiments $(1-10 \mathrm{~mL} / \mathrm{min})$ were carried out by passing $300 \mathrm{~mL}$ aqueous solution spiked with $1 \mu \mathrm{g}$ of each the PAEs. The sample loading rate was considered too fast when the recoveries of PAEs in eluate were below $90 \%$. The experimental results indicated that good recoveries were obtained when loading rate was between 1 and $5 \mathrm{~mL} / \mathrm{min}$; when loading rate increased to $8 \mathrm{~mL} / \mathrm{min}$, insufficient recoveries of $76,83,85,85$ and $84 \%$ for

Table 2

Analytical parameters of the proposed method

\begin{tabular}{llllll}
\hline Analytes & Linearity range $(\mu \mathrm{g} / \mathrm{L})$ & Correlation coefficient $\left(r^{2}\right)$ & LOD $(\mu \mathrm{g} / \mathrm{L})$ & Preconcentration factor & R.S.D. $(\%)(n=6)$ \\
\hline DEP & $0.6-50$ & 0.9912 & 0.17 & 600 & 5.9 \\
DnPP & $0.6-50$ & 0.9910 & 0.15 & 600 & 4.8 \\
DnBP & $0.6-50$ & 0.9924 & 0.13 & 600 & 5.2 \\
DcHP & $0.6-50$ & 0.9921 & 0.14 & 600 & 4.9 \\
DEHP & $0.6-50$ & 0.9918 & 0.12 & 600 & 4.1 \\
\hline
\end{tabular}


Table 3

Determination and recoveries of PAEs in real water samples

\begin{tabular}{|c|c|c|c|c|c|c|c|c|c|c|c|c|c|c|c|}
\hline Samples & \multicolumn{5}{|c|}{ Added $(\mu \mathrm{g} / \mathrm{L})$} & \multicolumn{5}{|c|}{ Founded $^{\mathrm{a}}(\mu \mathrm{g} / \mathrm{L})$} & \multicolumn{5}{|c|}{ Recovery $^{\mathrm{b}}(\%)$} \\
\hline Tap water & 0 & 0 & 0 & 0 & 0 & n.d. ${ }^{\mathrm{c}}$ & n.d. ${ }^{\mathrm{c}}$ & n.d. ${ }^{\mathrm{c}}$ & n.d. ${ }^{\mathrm{c}}$ & n.d. ${ }^{\mathrm{c}}$ & & & & & \\
\hline \multirow[t]{2}{*}{ Jingmi Canal } & 0 & 0 & 0 & 0 & 0 & 0.82 & n.d. ${ }^{\mathrm{c}}$ & 0.52 & n.d. ${ }^{\mathrm{c}}$ & 0.53 & & & & & \\
\hline & 1.0 & 1.0 & 1.0 & 1.0 & 1.0 & 1.78 & 0.87 & 1.46 & 1.02 & 1.49 & $96 \pm 5$ & $87 \pm 3$ & $94 \pm 5$ & $102 \pm 5$ & $96 \pm 4$ \\
\hline Xiaoqing River & 0 & 0 & 0 & 0 & 0 & 1.15 & n.d. ${ }^{\mathrm{c}}$ & 0.51 & 0.46 & 1.36 & & & & & \\
\hline & 1.0 & 1.0 & 1.0 & 1.0 & 1.0 & 0.93 & 0.87 & 1.58 & 1.36 & 1.47 & $93 \pm 4$ & $87 \pm 5$ & $91 \pm 4$ & $87 \pm 3$ & $95 \pm 5$ \\
\hline
\end{tabular}

\footnotetext{
a Mean of three determinations.

b S.D. for three determinations.

c Not detected.
}

DEP, DnPP, DnBP, DcHP and DEHP were obtained, respectively. Therefore, $300 \mathrm{~mL}$ solution volume and $5 \mathrm{~mL} / \mathrm{min}$ flow rate was selected for the next studies.

Desorption of PAEs from the $\left[\mathrm{C}_{12} \mathrm{mim}\right] \mathrm{Br}$-coated silica mixed hemimicelles column was studied with different organic solvent such as acetonitrile, methanol and methanol $(\mathrm{pH} \mathrm{2,}$ adjusted with $1 \mathrm{M} \mathrm{HNO}_{3}$ ). Quantitative recoveries (above 90\%) of PAEs were obtained using $3 \mathrm{~mL}$ methanol ( $\mathrm{pH} 2)$. When using $3 \mathrm{~mL}$ acetonitrile, the recoveries were $76,70,83,82$ and $79 \%$ for DEP, DnPP, DnBP, DcHP and DEHP were achieved, respectively, and a higher volume acetonitrile $(8 \mathrm{~mL})$ was required for desorbing the PAEs completely. When using $3 \mathrm{~mL}$ methanol, the recoveries were $81,76,85,82$ and $88 \%$ for DEP, DnPP, DnBP, DcHP and DEHP, respectively. Thus, $3 \mathrm{~mL}$ methanol (pH 2) was recommended for desorption. By drying the desorption solution with a nitrogen flow and redissolving the analytes in $0.5 \mathrm{~mL}$ methanol, the preconcentration factor of 600 for each PAEs was obtained.

\subsection{Analytical performance}

Quantitative parameters of the proposed method such as linear range, correlation coefficients, limits of detection (LODs) and relative standard deviation (R.S.D.), were evaluated by enriching $300 \mathrm{~mL}$ standard solutions (Table 2). Calibration curves were run using $300 \mathrm{~mL}$ deionized water spiked with $0.6-50 \mathrm{ng} / \mathrm{mL}$ each the PAEs. According to the overall SPE procedure and HPLC analysis method above-mentioned, the calibration curves were established. Each analyte exhibited good linearity with correlation coefficient $\left(r^{2}\right)>0.99$ in the studied range. The limits of detection, calculated on the basis of signalto-noise ratio of $3(\mathrm{~S} / \mathrm{N}=3)$ [45] ranged between 0.12 and $0.17 \mu \mathrm{g} / \mathrm{L}$. The precision of analytical method was investigated using six replicate experiments with $300 \mathrm{~mL}$ standard solution containing each the PAEs $1.0 \mu \mathrm{g} / \mathrm{L}$, and the relative standard deviation (R.S.D.) of below $6.0 \%$ was obtained.

\subsection{Analysis of real water samples}

In order to validate the method, the method was applied to four real environmental water samples with the results shown in
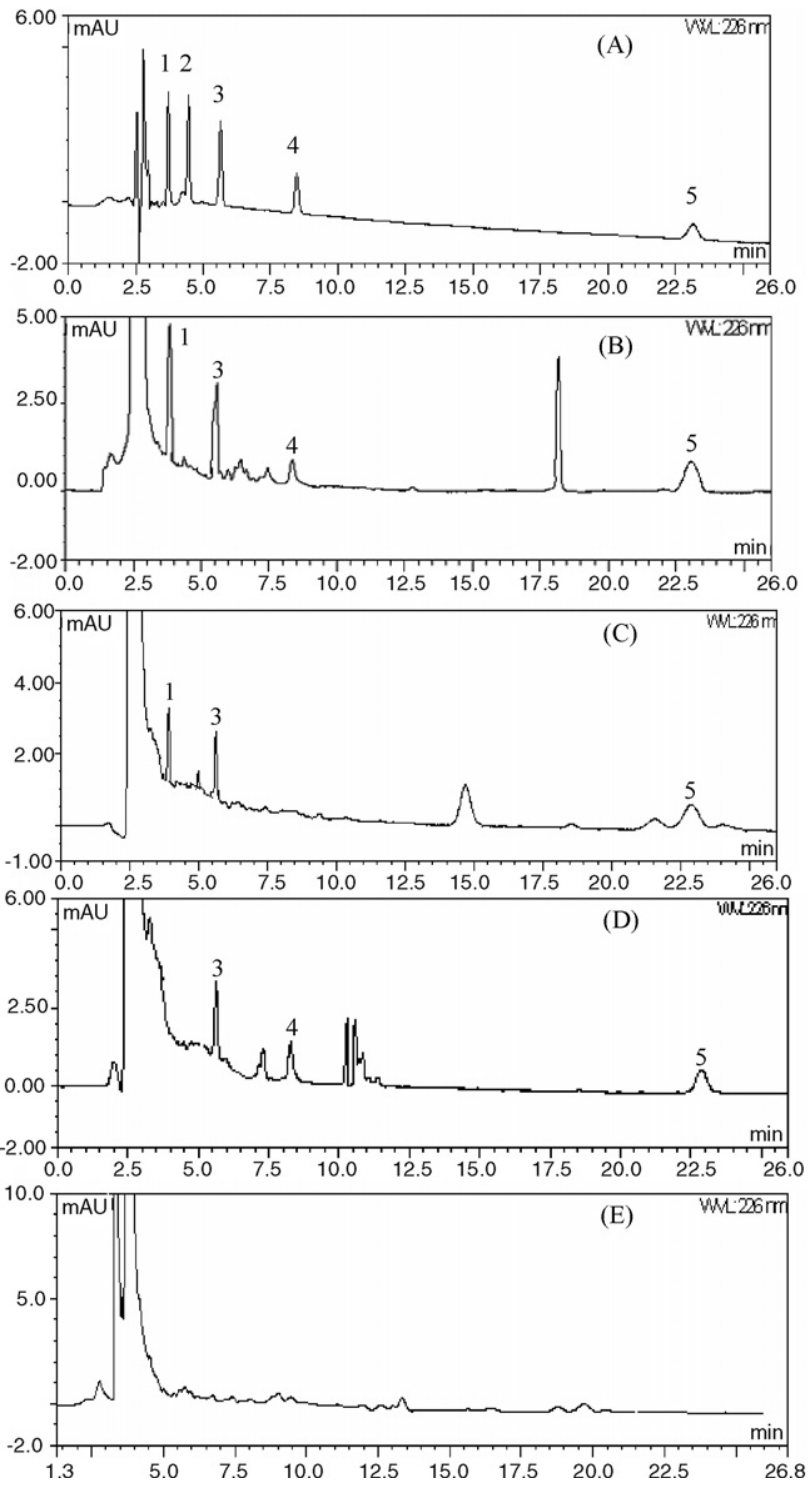

Fig. 5. Solid-phase extraction/LC-spectrophotometry chromatograms: (A) standard solution containing $0.3 \mathrm{mg} / \mathrm{L}$ of each the PAEs; (B) Xiaoqing River water sample; (C) Jingmi Canal; (D) Gaobeidian effluent; (E) tap water. (1) DEP; (2) DnPP; (3) DnBP; (4) DcHP; (5) DEHP. 
Table 3. No PAEs were found in the tap water; for the case of other three water samples, different PAE contents were found. The accuracy of the method was evaluated by a recovery test carried out with PAEs-spiked water samples. Recoveries ranged between 85 and 108\% for the five PAEs. The chromatograms of all the water samples were shown in Fig. 5.

\section{Conclusions}

A novel SPE method based on [ $\left.\mathrm{C}_{12} \mathrm{mim}\right] \mathrm{Br}$-coated silica mixed hemimicelles was developed for the analysis of five PAEs in four environmental water samples. The method was effective for the preconcentration of trace PAEs in environmental water prior to HPLC analysis. The strong hydrophobic interactions between the mixed hemimicelles and PAEs resulted in the high retention of analytes; however, the retained PAEs can be desorbed easily with $3 \mathrm{~mL}$ methanol ( $\mathrm{pH} 2$ ) and no carryover was observed in the next analysis. Good recovery and precision were obtained, which indicated that $\left[\mathrm{C}_{12} \mathrm{mim}\right] \mathrm{Br}$-coated silica mixed hemimicelles SPE method has high analytical potential for the preconcentration of other trace organic pollutants from water samples.

\section{Acknowledgments}

We gratefully acknowledge the support of this work by National Basic Research Program of China (2003CB415001), the National Natural Science Foundation of China (20577058, 20475060) and Major Research Program of Chinese Academy of Sciences (KZCX3-SW-432).

\section{References}

[1] A.C. Staple, D.R. Peterson, T.H. Parkerton, W.J. Adams, Chemosphere 35 (1997) 667.

[2] M. Castillo, A. Oubina, D. Barcelo, Environ. Sci. Technol. 32 (1998) 225.

[3] H.M. Koch, B. Rossbach, H. Drexler, J. Angerer, Environ. Res. 93 (2003) 177.

[4] C.R. Tyler, S. Jobling, J.P. Sumpter, Crit. Rev. Toxicol. (1998) 319.

[5] I. Coĺon, D. Caro, J. Carlos, C.J. Bourdony, O. Rosario, Environ. Health Perspect. 108 (2000) 895

[6] S.H. Swan, K.M. Main, F. Liu, S.L. Stewart, R.L. Kruse, A.M. Calafat, C.S. Mao, J.B. Redmon, Ch.L. Ternard, S. Sulivan, J.L. Teague, Environ. Health Perspect. 113 (2005) 1056.

[7] Y.L. Feng, J.P. Zhua, S. Robert, Anal. Chim. Acta 538 (2005) 41.

[8] E. Cortazar, O. Zuloaga, J. Sanz, J.C. Raposo, N. Etxebarria, L.A. Ferńandez, J. Chromatogr. A 978 (2002) 165.

[9] F. Jośe López-Jimenez, S. Rubio, D. Pérez-Bendito, Anal. Chim. Acta 551 (2005) 142

[10] D. DeOrsi, L. Gagliardi, R. Porra, S. Berri, P. Chimenti, A. Granese, I. Carpani, D. Tonelli, Anal. Chim. Acta 555 (2006) 238.
[11] C.S. Giam, M.K. Wong, J. Food Protect. 50 (1987) 769.

[12] K. Luks-Betlej, P. Popp, B. Janoszka, H. Paschke, J. Chromatogr. A 938 (2001) 93.

[13] G. Prokupkova, K. Holadova, J. Poustka, J. Hajslova, Anal. Chim. Acta 457 (2002) 211.

[14] H. Katsumata, A. Beguma, S. Kaneco, T. Suzuki, K. Ohta, Anal. Chim. Acta 502 (2004) 167.

[15] M.L. Davi, M. Liboni, M.G. Malfatti, Int. J. Environ. Anal. Chem. 74 (1999) 155

[16] S. Jonsson, H. Boŕen, J. Chromatogr. A 963 (2002) 393.

[17] Y.Q. Cai, G.B. Jiang, J.F. Liu, Q.X. Zhou, Anal. Chim. Acta 494 (2003) 149.

[18] F. Merino, S. Rubio, D. Pérez-Bendito, Anal. Chem. 76 (2004) 3878.

[19] M. Cantero, S. Rubio, D. Pérez-Bendito, J. Chromatogr. A 1067 (2005) 161.

[20] T. Saitoh, S. Matsushima, M. Hiraide, J. Chromatogr. A 1069 (2002) 271

[21] S.M. Mwonggela, A. Numan, N.L. Gill, R.A. Agbaria, I.M. Warner, Anal Chem. 75 (2003) 6089.

[22] E.G. Yanes, S.R. Gratz, M.J. Baldwin, S.E. Robinson, A.M. Stalcul, Anal Chem. 73 (2001) 3838

[23] J.L. Anderson, J. Ding, T. Welton, D.W. Armstrong, J. Am. Chem. Soc. 124 (2002) 14247.

[24] M.S. Selvan, M.D. Mckinley, R.H. Dubois, J.L. Atwood, J. Chem. Eng. Data 45 (2000) 841.

[25] J. Liu, J. Peng, Y. Chi, G. Jiang, Talanta 65 (2005) 705.

[26] R. Sridhar, P.T. Perumal, Tetrahedron 61 (2005) 2465.

[27] N.E. Leadbeater, H.M. Torenius, J. Org. Chem. 67 (2002) 3145.

[28] L.A. Blanchard, D. Hancut, E.J. Beckman, J.F. Brennecke, Nature 399 (1999) 28.

[29] A.E. Visser, R.D. Rogers, J. Solid State Chem. 171 (2003) 109.

[30] P.Y. Chen, C.L. Hussey, Electrochim. Acta 50 (2005) 2533.

[31] E.V. Dickinson, M.E. Willaims, S.M. Hendrickson, H. Masui, R.W. Murray, J. Am. Chem. Soc. 121 (1999) 613.

[32] Z. Miskolczy, K. Sebok-Nagy, L. Biczok, S. Gokturk, Chem. Phys. Lett. 400 (2004) 296.

[33] P. Wasserscheid, W. Keim, Angew. Chem. Int. Ed. 39 (2000) 3772.

[34] T. Welton, Chem. Rev. 99 (1999) 2071.

[35] D.W. Armstrong, L. He, Y.S. Liu, Anal. Chem. 71 (1999) 3873.

[36] D.W. Armstrong, L. Zhang, L. He, M.L. Gross, Anal. Chem. 73 (2001) 3679.

[37] D. Giovanelli, M.C. Buzzeo, N.S. Lawrence, C. Hardacre, K.R. Seddon, R.G. Compton, Talanta 62 (2004) 904.

[38] C.H. She, H. Li, H.W. Liu, K.A. Li, F. Liu, J. Chromatogr. A 1082 (2005) 143.

[39] S.H. Li, C.Y. He, H.W. Liu, K.A. Li, F. Liu, J. Chromatogr. B 826 (2005) 58.

[40] K. Nagashima, F.D. Blum, J. Colloid Interf. Sci. 214 (1999) 8.

[41] A. Fan, P. Somasundaran, N.J. Turro, Langmuir 506 (1997) 13.

[42] V.K. Paruchuri, A.V. Nguyen, J.D. Miller, Colloids Surf. A 250 (2004) 519.

[43] C.E. McNamee, M. Matsumoto, P.G. Hartley, M. Nakahara, Colloids Surf. A 193 (2001) 175.

[44] N.K. Dimov, V.L. Kolev, P.A. Kralchevsky, L.G. Lyutov, G. Broze, A Mehretea, J. Colloid Interf. Sci. 256 (2002) 23.

[45] I. Taverniers, M.D. Loose, E. Van Bocstaele, Trends Anal. Chem. 23 (2004) 535. 